\title{
Earthquake Science: a New Start
}

Understanding the mechanisms which cause earthquakes and thus earthquake prediction, is inherently difficult in comparison to other physical phenomena. This is due to the inaccessibility of the Earth's interior, the infrequency of large earthquakes, and the complexities of the physical processes involved. Consequently, in its broadest sense, earthquake science-the science of studying earthquake phenomena, is a comprehensive and inter-disciplinary field. The disciplines involved in earthquake science include: traditional seismology, earthquake geodesy, earthquake geology, rock mechanics, complex system theory, and information and communication technologies related to earthquake studies.

Despite the tremendous difficulties encountered in the studies of earthquakes, significant advances were made in the last few decades due to the rapid development and growth of new seismic and geodetic networks, new methods for deciphering the geological records of earthquakes, the creation of powerful models through the application of high-performance computers, and increased inter-disciplinary interaction in earthquake science.

In 1979 Acta Seismologica Sinica (ASS) was launched to promote scientific and technological exchanges among scientists so as to improve our understanding of earthquake phenomena with the aim of preventing and mitigating earthquake hazards. In 1988, Seismological Society of China began publishing English articles in the journal and now on the 30th anniversary of its foundation the Seismological Society of China has decided to separate the English edition of the
ASS from the Chinese edition, and to publish it independently under the title of Earthquake Science starting Issue 1, 2009.

Earthquake Science is intended for both academic and professional scientists and engineers involved in earthquake science in China and abroad. The main topics covered include but are not limited to: (1) results of basic and applied research in earthquake science, i.e., traditional seismology, earthquake geodesy, earthquake geology, and rock mechanics, complex system theory, and information and communication technologies related to earthquake studies; (2) articles presenting different scientific points of views in the field of earthquake science; (3) reviews of and advances in research related to earthquake science; (4) comments and discussion concerning earthquake science; (5) the latest trends in earthquake science.

Earthquake Science welcomes the submission of English-written papers and will persist in upholding the original principles of the journal and in making every effort to publish innovative results from earthquake studies in China and abroad.

In the past three decades since the publication of the $A S S$, we have benefited from a huge amount of help and support from the authors, readers and reviewers of $A S S$, to whom we would like to take this opportunity to express our sincere thanks and ardent expectation of their continuing support in the years to come.

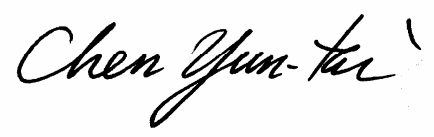

Prof. Chen Yun-tai

Editor-in-Chief, Earthquake Science 